\title{
Use of Online Public Access Catalogue at Annamalai University Library
}

\author{
S. Thanuskodi
}

Department of Library and Information Science Alagappa University, 630 003, Karaikudi

\begin{abstract}
The patrons in the library can search the bibliographic database and find specific in formation online. The search facility also aprises the user about the availability of each item for circulation, including current status of individual copies of a title and reserve status. It also shows titles on order displaying current status in acquisition. This paper examines Online Public Access Catalogue usage by the students, research scholars and faculty of Annamalai University Library. A questionnaire-based survey on use of OPAC was conducted for Annamalai University Library on various categories of users such as faculty members, research scholars and postgraduate students, covering different disciplines such as Arts, Science, Engineering, Medicine and Agriculture sciences. The paper discusses various aspects of OPAC such as frequency of use, purpose, satisfaction level, etc. The results of the study show that only one third of the respondents used OPAC frequently. The study also found that majority of users consulted OPAC to know the availability and location of the requisite documents.
\end{abstract}

Keywords On line Public Access Catalogue (OPAC), University Library, Information, Card Catalogue, Bibliographic Records, Internet Resources

\section{Introduction}

The Online Public Access Catalogue (OPAC) is an information retrieval system characterized by short bibliographic records, mainly of books, journals, and audiovisual materials available in a particular library. This, coupled with a Boolean search interface and a heterogeneous user population with diverse needs, presents special problems for subject searching by end users. To perform effective subject searching in the OPAC system requires a wide range of knowledge and skills. Various approaches to improving the OPAC design for subject searching have been proposed and are reviewed in this article. The trend toward Web-based OPAC interfaces and the developments in Internet and digital library technologies present fresh opportunities for enhancing the effectiveness of the OPAC system for subject searching.

\section{Online Public Access Catalogue (OPAC)}

An OPAC database records are usually derived from the MARC format. The records are brief bibliographic descriptions enriched with a small number of controlled

* Corresponding author:

thanuskodi_s@yahoo.com (S. Thanuskodi)

Published online at http//journal.sapub.org/ijis

Copyright (C) 2012 Scientific \& Academic Publishing. All Rights Reserved subject descriptors (often taken from the Library of Congress Subject Headings) and a classification number (usually a Library of Congress or a Dewey decimal class number). The database records, thus, contain minimal information for searching - little more than the author, title, publication year, subject description, and a class number. The subject descriptors are selected to reflect the subject content of the item as a whole rather than to provide in-depth indexing of the information contained in the item. For example, if a book contains many articles, subject descriptors are not assigned for each article but only to the overall topic of the book. For periodical publications, only the periodical as a whole is described. Individual journal articles are usually not recorded in the database. This is in contrast to indexing and abstracting databases that provide keyword searching in the abstract and even the full text of articles, and provide exhaustive indexing of the content of journal articles. However, the distinction between OPACs and other kinds of information retrieval systems is blurring. Increasingly, OPACs are also providing links to full-text document, electronic books, and Internet resources.

Most of the online catalogs in use today are what Hildreth termed second-generation OPACs. Most OPACs are Boolean retrieval systems that perform exact matching and require the search query to be specified as a Boolean expression. Typical search features include the choice of keyword searching (i.e., searching for individual words in the title and subject fields) or field searching with automatic truncation (e.g., searching for a whole title or author name), the use of Boolean operators to combine two or more terms, 
the use of a truncation symbol, and limiting a search to specific fields. The onus is on the user to translate the user's information need into the subject headings and indexing terms used in the OPAC database and to refine the search based on the initial search result. Because most OPAC systems now offer Web access, OPAC interfaces are increasingly Web interfaces in the form of web pages containing HTML forms. Such interfaces are mainly form-filling interfaces. The user selects the type of search and the fields for searching either by entering the query in the appropriate input box or by toggling the appropriate checkbox or radio button. For keyword searching, the search expression can include Boolean operators as well as indications of which field(s) to search[1].

OPAC users are heterogenous, varying widely in background, age, subject interests, and computer and information literacy. So the OPAC has to be designed to cater to a wide range of users, ranging from users who have little knowledge of what a catalog contains and have little experience with computer terminals to librarians who are experienced in on line database searching and who require the system to have powerful search capabilities.

\section{Literature Review}

The first library online public access catalogue was introduced in the early 1980s and researchers have been conducting usability studies of these catalogs ever since. In designing our usability study, we incorporated what we felt to be some of the best, most useful methods from previous research. However, our research is unique in that it compares four different library OPACs (both academic and public) fro $m$ a specific geographic location, Seattle.

In 1999, Chisman, Diller, and Walbridge conducted a usability study of the Washington State University Library OPAC. The library was preparing to implement a new version of the OPAC, and before it did so, wanted to test how usable the new catalog was, test whether or not people understood its features, and incorporate participants' feedback into the design of the new OPAC. Chis man, Diller, and Walbridge found that most of the OPACs problems were related to subject indexes and article databases; participants could not find and did not understand how to use these features[2].

In 2002, Halcoussis et al conducted a usability study of California Institute of the Arts Library OPAC to identify "causative factors determining catalog user success in finding in formation, user attitudes to catalog organization, and user ability to navigate the catalog (p. 148)." These researchers had participants conduct four different kinds of searches, took observation notes, and then had participants answer evaluative questions about the catalog. Halcouss is et al discovered that subject-searchers are more likely to run into difficulty while using the library catalog and are therefore more likely to view the catalog in a negative way. Also, users who spend a lot of time on a search and retrieve a large number of search results are also more likely to report having difficulty using the OPAC[3].

In 2004, Novotny conducted a protocol analysis study to determine the usability of the Pennsylvania State University Library OPAC. Participants were to complete five structured tasks using the catalog and were to tell observers exactly what they were thinking while they completed each task. Researchers found that the use of internet search engines has had a profound effect on the way that library patrons try to use and the expectations that they have for library OPACs. Because library OPACs are not necessarily designed to work in the same way as internet search engines, this created some problems for participants and highlighted areas of the catalog that could be modified to help users search more effectively [4].

\section{Objectives of the Study}

The main objectives of the present study are as follows:

- To access as to what extent the users are using OPAC

- To find out the purpose of use of OPAC

- To know whether the users face problems while using OPAC

- To study the satisfaction of users while using OPAC

\section{Scope of the Study}

The present study included postgraduate students, research scholars and faculty members of Annamalai University Library. The main aim of the study was to assess the purpose, knowledge and frequency of using OPAC and problems faced by users. A sample of 400 users was taken covering various disciplines such as Arts, Science, Engineering, Medicine and Agriculture sciences.

\section{Methodology}

A questionnaire was designed to gather primary data which was distributed among 400 users of Annamalai University Library during academic year 2010-2011. Proper care was taken to select the representative sample from each category proportionately on the basis of total strength of category concerned. A total of 268 out of 400 respondents completed and returned the questionnaires giving overall, a response rate of 67 per cent.

\section{Data Analysis}

Analysis of data is the ultimate step in research process. It is the link between raw data and significant results leading to conclusions. This process of analysis has to be result oriented.

\subsection{Population Study}


Personal detail section of the questionnaire provides information regarding the sex and different qualifications as can be seen from Table-1. It is shown in table-1, $73.14 \%$ of population studied were ma les and only $26.86 \%$ of total were females.

Table 1. Sex wise distribution of Respondents

\begin{tabular}{|c|c|c|}
\hline Gender & No. of Respondents & Percentage \\
\hline Male & 196 & 73.14 \\
\hline Female & 72 & 26.86 \\
\hline Total & 268 & 100.00 \\
\hline
\end{tabular}

Table 2. Category wise distribution of Respondents

\begin{tabular}{|c|c|c|}
\hline Academic Status & No. of Respondents & Percentage \\
\hline Post Graduate Students & 136 & 50.74 \\
\hline Research Scholars & 58 & 21.64 \\
\hline Faculty Members & 74 & 27.62 \\
\hline Total & 268 & 100.00 \\
\hline
\end{tabular}

Table-2 shows that $50.74 \%$ of the respondents were post graduate students, $21.64 \%$ were research scholars and $27.62 \%$ were faculty members.

\subsection{Freque ncy of Using OPAC}

Table 3. Frequency of using OPAC

\begin{tabular}{|c|c|c|}
\hline Frequency & No.of Respondents & Percentage \\
\hline Frequently & 84 & 31.35 \\
\hline Occasionally & 68 & 25.38 \\
\hline Rarely & 56 & 20.89 \\
\hline Never & 60 & 22.38 \\
\hline Total & 268 & 100.00 \\
\hline
\end{tabular}

It is important to know how frequently the users use OPAC to locate their required documents. The frequency of using OPAC indicates its value in the library. Table-3 indicates the frequency of OPAC use. The table depicts that out of total 268 users only $31.35 \%$ respondents frequently used the OPAC, $25.38 \%$ of respondents used occasionally, $20.89 \%$ of respondents used rarely and $22.38 \%$ of respondents never used OPAC. Table- 3 further shows that only one third of the respondents used OPAC frequently.

\subsection{Problems for never Using OPAC}

Table 4. Problems for never using OP AC

\begin{tabular}{|c|c|c|}
\hline Reasons & No. of Respondents & Percentage \\
\hline Lack of knowledge & 57 & 95.00 \\
\hline Confusing to use & 42 & 70.00 \\
\hline No output & 31 & 51.66 \\
\hline $\begin{array}{c}\text { Lack of assistance from library } \\
\text { staff }\end{array}$ & 27 & 45.00 \\
\hline Slow speed & 22 & 36.66 \\
\hline Lack of computer systems & 15 & 25.00 \\
\hline
\end{tabular}

As presented in Table 3, among the respondents, 60 $(22.38 \%)$ never used OPAC. These respondents were asked to give the reasons for never using OPAC. Tab le 4 shows that $95 \%$ of 60 respondents expressed lack of knowledge, $70 \%$ expressed confusing to use, $51.66 \%$ expressed no output, $45 \%$ expressed lack of assistance from lib rary staff, $36.66 \%$ expressed slow speed and around one fourth expressed lack of computer systems.

\subsection{Alternative Methods Used by the Users}

Table 5. Alternative methods used by the users

\begin{tabular}{|c|c|c|}
\hline Alternative methods & No. of Respondents & Percentage \\
\hline Consult card cat alogue & 35 & 58.33 \\
\hline Search shelves individually & 48 & 80.00 \\
\hline Ask library staff & 26 & 43.33 \\
\hline Ask friends & 17 & 28.33 \\
\hline
\end{tabular}

The opinions regarding alternative methods used by the users who never used OPAC are represented in Table 5. Out of 60 users $58.33 \%$ consulted card catalogue to search the documents, $80 \%$ searched the library shelves themselves. Further, $43.33 \%$ seeked the help from library staff to find out the documents, and $28.33 \%$ seeked the help from the friends. Thus, it is clear from Table 5 that majority of these users preferred to search shelves or consult card catalogue to find the required documents.

\subsection{Purpose of Using OPAC}

Table 6. Purpose of using OPAC

\begin{tabular}{|c|c|c|}
\hline Purpose of using OPAC & No. of Respondents & Percentage \\
\hline $\begin{array}{c}\text { To know the availability of } \\
\text { requisite documents }\end{array}$ & 154 & 74.03 \\
\hline $\begin{array}{c}\text { To know whether requisite } \\
\text { document issued }\end{array}$ & 87 & 41.82 \\
\hline $\begin{array}{c}\text { To know the location of } \\
\text { requisite document }\end{array}$ & 163 & 78.36 \\
\hline
\end{tabular}

Table 6 shows the purpose of using OPAC is indicated. It depicts that $74.03 \%$ of users consulted OPAC to know the availability of the requisite document in the library, $41.82 \%$ to know whether the requisite document issued and $78.36 \%$ to know the location of the requisite documents. It is clear from Table 6 that majority of users consulted OPAC to know the availability and location of the requisite documents.

\subsection{Availability of Library Staff in the Vicinity of OPAC}

Table 7. Availability of Library Staff in the vicinity of OPAC

\begin{tabular}{|c|c|c|}
\hline Availability of staff & No. of Respondents & Percentage \\
\hline Always & 77 & 37.01 \\
\hline Usually & 56 & 26.93 \\
\hline Occasionally & 38 & 18.26 \\
\hline Rarely & 24 & 11.54 \\
\hline Never & 13 & 6.26 \\
\hline Total & 208 & 100.00 \\
\hline
\end{tabular}

Table 7 shows the responses about the availability of library staff to assist the users for using OPAC. The Table reveals that only $37.01 \%$ users found that library staff was 
always available near OPAC, $26.93 \%$ found library staff usually available, $18.26 \%$ found occasionally available, $11.54 \%$ found rarely available and $6.26 \%$ found never available near OPAC.

\subsection{Sufficiency of Computers for OPAC Use}

Table 8. Sufficiency of Computers for OP AC use

\begin{tabular}{|c|c|c|}
\hline Sufficiency of computers & No. of Respondents & Percentage \\
\hline Strongly Agree & 37 & 17.78 \\
\hline Agree & 82 & 39.43 \\
\hline Neutral & 45 & 21.63 \\
\hline Disagree & 28 & 13.47 \\
\hline Strongly Disagree & 16 & 7.69 \\
\hline Total & 208 & 100.00 \\
\hline
\end{tabular}

Table- 8 represents the opinions of respondents about the sufficiency of computers available in the library for OPAC use. Table shows that only $17.78 \%$ users strongly agreed that the number of computers was sufficiency, more than one third of users agreed with availability of co mputers, $21.63 \%$ were neutral about it, $13.47 \%$ were disagreed with availability of computers, and very few $7.69 \%$ strongly disagreed with availability of computers. It is clear from Table 15 that majority of users opined that the number of computers was sufficiency for OPAC use.

\subsection{Res ponse Time for Displaying Results}

Table 9. Response Time for Displaying Results

\begin{tabular}{|c|c|c|}
\hline Speed of displaying the results & No. of Respondents & Percentage \\
\hline Very fast & 29 & 13.95 \\
\hline Fast & 98 & 47.12 \\
\hline Moderately fast & 28 & 13.47 \\
\hline Slow & 36 & 17.30 \\
\hline Very slow & 7 & 3.36 \\
\hline Total & 208 & 100.00 \\
\hline
\end{tabular}

The respondents were asked to indicate how fast OPAC system displayed the results after a search. The data related to this query is depicted in Table 9. A mong the respondents, $13.95 \%$ said very fast display of the results after a search, $47.12 \%$ said fast display of the results, $13.47 \%$ said moderately fast display of the results, $17.30 \%$ said slow display of the results, and very few $3.36 \%$ said very slow display of the results. It is evident that a large majority of users around $60 \%$ feel that the display of the results after a search was fast.

\subsection{Over all Satisfaction Level in Using OPAC}

Table 10. Overall Satisfaction Level in Using OPAC

\begin{tabular}{|c|c|c|}
\hline Satisfaction Level & No. of Respondents & Percentage \\
\hline Fully sat isfied & 42 & 20.19 \\
\hline Satisfied & 87 & 41.83 \\
\hline Moderately satisfied & 61 & 29.33 \\
\hline Dissatisfied & 13 & 6.25 \\
\hline Very dissatisfied & 5 & 2.40 \\
\hline Total & 208 & 100.00 \\
\hline
\end{tabular}

Table 10 exhibits overall satisfaction level of users in using OPAC. It highlights that out of 208 users around one fifth of the users $20.19 \%$ were fully satis fied with OPAC use, almost half of the respondents were satis fied and one-third moderately satisfied with OPAC use. Only $6.25 \%$ were dissatisfied with OPAC use and $2.40 \%$ were very dissatisfied with OPAC use. Evidently, it is clear that only majority of users is satisfied with OPAC working.

\section{Conclusions}

We also come to the evident conclusion that the interface of the OPAC of the Annamalai University was not optimal for serving user needs, with apparent limitations in its design, a lack of screens for assistance, a deficient system of searching by subject heading, and very limited search options. Users have many kinds of problems performing subject searches in OPAC systems. Typicalusers do not have the range of knowledge and skills needed for effective subject searching. This article has surveyed possible improvements that can be made to OPAC system design. With developments in Internet and Web browser technologies, many of the proposed improvements can be instituted without major changes to the OPAC back end system. Changes can easily be made in the design of the web pages used as an interface to the OPAC. OPAC interfaces are playing increasingly expanded roles. They now provide access not just to records of books and journals held by a library but also to multiple library systems, to full-text documents and journal articles, and to databases and other resources on the Internet.

\section{Recommendations}

On the basis of the findings, the following recommendations have been made for optimu mutilisation of OPAC facility in the University lib rary:

- The study observed that the OPAC does not offer various essential features such as spell check software, quick search, online reservation, online renewal, new arrivals and book cover display facilities. Moreover these features, there is no provision for links to electronic sources. Therefore, it is strongly recommended that the said features must be incorporated in OPAC.

$\checkmark$ OPAC should have more user-friendly online help that may provide direction to users to start a search and to show next steps during a search.

- To facilitate the users, the University library should organise user education programmes on the use of different techniques and strategies in retrieving information about the documents. The instruction programmes may enhance user knowledge and basic skills for searching OPAC.

- It is evident from the study that the users were not having basic skills of searching OPAC. Therefore, they needed the assistance of library staff near OPAC terminals for optimu mutilisation of this service. 


\section{REFERENCES}

[1] Hildreth, C.R. Pursuing the Ideal: Generations of Online Catalogs. In Online Catalogs, Online Reference: Converging Trends; Aveney, B., Butler, B., Eds.; American Library Association: Chicago, 31-57, 1984.

[2] Chisman, J., Diller, K., \& Walbridge, S. Usability testing: A case study. College \& Research Libraries, 60(6), 552-569. 1999.

[3] Halcoussis, D., Halverson, A.L., Lowenberg, A.D., \& Lowenberg, S. An empirical analysis of web catalog user experiences. Information Technology and Libraries, 21(4), 148-157, 2002.

[4] Novotny, E. I don't think I click: A protocol analy sis study of use of a library online catalog in the internet age. College \& Research Libraries, 65(6), 525-537, 2004. 